\title{
Características de jogos educacionais para adultos mais velhos em processo de alfabetização
}

\author{
Renata Cristina Santana, PUC Minas, renata.cris.santana@gmail.com \\ Lucila Ishitani, PUC Minas, lucila@pucminas.br
}

\begin{abstract}
RESUMO. Este trabalho teve como objetivo identificar as principais características de jogos educacionais necessárias para auxiliar adultos mais velhos (AMV) no processo de alfabetização. A pesquisa foi delineada por meio de um estudo de caso. AMV foram observados jogando quatro jogos educativos. Após cada sessão de jogos foi respondido um questionário sobre a experiência com os jogos e, ao término, foi feita uma entrevista. Além disso, dez especialistas na área de informática responderam a um questionário de avaliação dos jogos baseado em heurísticas de jogabilidade. Foi observado que para que haja o sucesso dos jogos digitais no processo de alfabetização é preciso considerar as especificidades dos AMV e suas limitações físicas e permitir adaptações didáticas necessárias a cada AMV individualmente.
\end{abstract}

Palavras-chave: Jogos digitais. Adultos mais velhos. Características de jogabilidade.

ABSTRACT. This work aimed to identify the main game features that may help older people in the literacy process. The research was delineated as a case study. Six older people were observed playing four educational games. After each game session one game experience questionnaire was filled out and, after all sessions, a final interview was performed. Besides, ten professionals from the Information Systems area filled out a game evaluation questionnaire based on playability heuristics. It was observed that in order to get success in the literacy process digital games design must consider the specificities of the older people, including their physical limitations and support to pedagogical adaptations needed by each older person.

Keywords: Digital games. Older people. Playability features.

\section{Introdução}

Os dados demográficos do censo de 2010 (IBGE, 2013) mostram que o Brasil não é mais um "país jovem". De acordo com o Instituto Brasileiro de Geografia e Estatística (IBGE), as pessoas com sessenta anos ou mais representam 10,8\% da população. $\mathrm{O}$ aumento da proporção de pessoas acima de 45 anos na população é consequência da redução da taxa de natalidade e aumento da expectativa de vida. Ainda de acordo com esse censo, a população brasileira era de cerca de 195 milhões de pessoas em 2010 (195.497.797). Dessas, cinquenta milhões (50.063.207) eram pessoas com 45 anos ou mais. Além disso, de acordo com a projeção do censo, o número de pessoas mais velhas continuará crescendo até 2060 , enquanto a população total tende a diminuir.

Dentre esse público, segundo dados do IBGE, o número de pessoas mais velhas analfabetas é grande: em 2010 o Brasil tinha 13.933.173 pessoas que não sabiam ler ou escrever, sendo que 39,2\% desse contingente era de pessoas acima de sessenta anos, o que totalizava 5.461.803 pessoas, aproximadamente. Segundo o IBGE (2013), cerca de $56 \%$ do grupo de analfabetos no Brasil tem idade acima de 55 anos, enquanto que, em 2002, apenas $45 \%$ tinha essa faixa etária nesse grupo. Além de já existirem adultos mais 
velhos não alfabetizados, o processo educacional ainda tem brechas que continuam permitindo que crianças e adolescentes saiam da escola sem saber ler e escrever. Segundo IBGE (2010), 6,8\% da população brasileira entre 7 a 14 anos não sabem ler e nem escrever. Por este motivo, jogos elaborados para atender a esse público podem contribuir no campo da educação.

Ijsselsteijn et al. (2007) afirmam que os jogos digitais podem contribuir para melhorar a vida dos idosos, mas para que isso ocorra, é preciso desenvolver jogos que sejam interessantes e acessíveis a esse grupo. Os autores complementam dizendo que existe "a necessidade crescente de oferecer alternativas de entretenimento e aprendizagem a esse público" (Ijsselsteijn et al., 2007, p. 20).

Segundo Carvalho e Ishitani (2013) é possível afirmar que jogos sérios contribuem no processo de ensino/aprendizagem. Além disso, a população de idosos está crescendo no mundo e, de forma acelerada, no Brasil. Também é sabido que essa população carece de meios alternativos para se manter ativa cívica e socialmente. Nesse contexto fica a questão: quais características um projeto de jogo sério deve conter para auxiliar no processo de alfabetização de adultos mais velhos?

Outra dificuldade a ser enfrentada é a padronização de um termo que nomeie pessoas nessa faixa etária. Neste trabalho foi utilizado o termo "adultos mais velhos" (AMV) para referenciar os participantes da pesquisa que foram observados. Tais participantes tinham entre 46 e 81 anos de idade na época do estudo.

A presente pesquisa parte, pois, da premissa de que os jogos sérios, por relacionarem a prática educativa ao entretenimento, podem configurar uma opção viável e estimulante para esse perfil de educando, contribuindo para a inclusão dos AMV em seu meio social ao estabelecer uma ponte com o mundo de forte apelo tecnológico em que essas pessoas vivem (Browne et al., 2014).

Trabalhos científicos que se preocupem com as necessidades específicas de adultos mais velhos em relação aos jogos contribuem na medida em que podem ajudar na melhoria de projetos de jogo e, consequentemente, dos próprios jogos. Tais jogos podem promover avanços na área da saúde, na inclusão digital das pessoas mais velhas e, mais especificamente, no processo de alfabetização dessas pessoas (Silva; Roque, 2014; Browne et al., 2014). Pensar nisso se torna cada vez mais importante, uma vez que em um futuro bem próximo, eles serão a maioria na população mundial (Tambascia et al., 2008; Gonçalves et al., 2011; Sales et al., 2013).

O objetivo geral deste trabalho é, por meio de um estudo de caso, levantar as características necessárias a um projeto de jogo educacional para auxiliar adultos mais velhos no processo de alfabetização.

\section{Metodologia}

O delineamento da pesquisa foi feito por meio de um estudo de caso, que norteou o planejamento e a elaboração dos instrumentos de pesquisa. Detalhes sobre a esses instrumentos de pesquisa, os participantes do estudo de caso, os procedimentos adotados e a análise de dados são apresentados nas seções que se seguem.

\subsection{Amostra}

Dois grupos de participantes foram escolhidos. O Grupo 1 era composto por três alunos acima de 46 anos, em processo de alfabetização, estudantes da modalidade de ensino Educação de Jovens e Adultos (EJA) da Rede Municipal de Educação de Belo 
Horizonte. O Grupo 2 era composto por três pessoas acima de 46 anos que não concluíram o processo de alfabetização, mas que não frequentavam uma instituição escolar à época da realização deste estudo.

Para citar os participantes sem identificá-los, utilizou-se a seguinte nomenclatura: A1, A2 e A3, para integrantes do Grupo 1, os alunos, e P1, P2 e P3 para integrantes do Grupo 2, os participantes. Entretanto, em situações onde não importa essa distinção, as pessoas são designadas apenas como "participantes", que é o caso do início da sentença anterior, neste parágrafo.

Todos os participantes assinaram o termo de consentimento livre e esclarecido e foram informados sobre o objetivo e a forma de realização da avaliação. Os responsáveis pela escola municipal que os alunos do Grupo 1 frequentavam, também assinaram um termo de compromisso declarando estarem cientes da realização da pesquisa.

\subsection{Instrumentos de pesquisa}

Três instrumentos de pesquisa foram utilizados: observação, um questionário aplicado ao final de cada semana e entrevistas inicial e final.

Os integrantes do Grupo 1 foram observados jogando durante um mês, três dias por semana, no período de uma hora por dia, totalizando doze horas. Para não interferir no cotidiano de tais integrantes o local escolhido foi a própria escola em que estudavam. O objetivo foi apreender informações sobre o ambiente em que estão inseridos no contexto educacional. As datas e os tempos foram decididos em comum acordo com a direção da escola e o professor.

Os integrantes do Grupo 2 foram observados jogando no mesmo período de tempo que o Grupo 1, em suas respectivas residências. Dessa forma, eles não necessitaram se deslocar, fato que poderia desmotivá-los ou impedi-los de participar.

O questionário adotado foi intitulado "Experiência com jogos" e se baseou na proposta dos autores Ijsselsteijn, Kort e Poels ${ }^{1}$. O questionário original é composto por quatro módulos: módulo principal, módulo in-game, módulo de presença social e módulo pós-jogo, totalizando 81 perguntas. Para esta pesquisa, dois dos módulos, ingame e módulo de presença social, não foram utilizados. O primeiro, por se tratar de perguntas que levam em consideração gamers experientes e o último por se referir a jogos com mais de um jogador, o que não é o caso dos jogos selecionados para esta pesquisa.

A entrevista estruturada era composta de onze perguntas que mapeavam como foi a experiência com os jogos. O objetivo foi captar a percepção que os jogadores tiveram em relação às suas emoções e ao jogo em si.

\subsection{Procedimentos}

Para detectar o conhecimento prévio dos participantes, tanto no processo de alfabetização, quanto em informática, três procedimentos foram adotados: 1) Entrevista com o professor da escola municipal responsável pela turma que os alunos integravam, com o objetivo de conhecer o perfil dos alunos que ele atendia e o uso que ele fazia dos jogos digitais como recurso didático em sala de aula. 2) Entrevista inicial com os

\footnotetext{
${ }^{1} \mathrm{O}$ questionário utilizado neste trabalho foi enviado por e-mail para a Prof ${ }^{a}$. Lucila Ishitani, por um dos autores (Ijsselsteijn, W. A.). Trata-se de trabalho cujo manuscrito para publicação está em preparação na data da redação deste artigo.
} 
participantes, para identificar o conhecimento em informática e em jogos digitais e a percepção que eles têm de jogos, além de coletar alguns dados demográficos. Esses dados auxiliaram posteriormente na seleção de jogos educativos que contemplassem as limitações existentes nos grupos. 3) Avaliação diagnóstica composta por questões retiradas ou baseadas em um documento publicado pelo Ministério da Educação (BRASIL, 2007), que visa instruir escolas do Brasil inteiro sobre avaliações diagnósticas para detectar as etapas vencidas pelos estudantes no processo de alfabetização.

O professor dos participantes do Grupo 1 atende alunos que não se adaptaram à sala de aula com um número maior de estudantes e que precisam de atendimento individualizado para avançar no processo de alfabetização. Nesse processo, ele já utilizava jogos digitais, esporadicamente, com os alunos. Por esse motivo, tinha uma lista de sites com conteúdos educativos. A seleção dos jogos foi feita a partir dessa lista de links para jogos educativos. O objetivo foi tentar minimizar as interferências do pesquisador no contexto pesquisado, uma vez que tais jogos já teriam passado pelo crivo do educador que acompanha os alunos desde o início do ano letivo e que, possivelmente, atendem às necessidades desses educandos segundo os critérios do professor.

Depois de visitar cada link listado pelo educador, os jogos foram selecionados segundo os critérios: 1) Jogos divulgados diretamente no site, ou seja, não exigiam selecionar outro link para encontrá-los. Tal critério foi utilizado, pois em vários sites existiam links para outros sites e desses para outros, o que impossibilitou o exame de todos, dado o grande número de sites a visitar. 2) Jogos que explicitamente se intitulavam como jogos educativos. 3) Jogos explicitamente de alfabetização. 4) Jogos explicitamente de língua portuguesa. 5) Jogos que atendiam ao nível de alfabetização detectado na avaliação diagnóstica. Os jogos selecionados foram: "Forma palavras", "Ditado", "Brincando com as vogais" e "A procura das cartas" (Games, 2015).

Os registros das observações foram feitos através de transcrição e gravação de falas, além de gravação de vídeos e fotografias enquanto jogavam. Em cada semana foi utilizado um jogo diferente.

Para jogar, tanto os componentes do Grupo1 quanto os componentes do Grupo 2, ficavam em mesas individuais com um computador. $\mathrm{O}$ pesquisador entrava no site selecionava o jogo e deixava o participante ler as instruções e clicar em "Jogar". Só foram feitas intervenções quando os alunos solicitavam. E isso foi combinado no início das sessões.

Ao final de cada semana os jogadores respondiam ao questionário "Experiência com jogos". Ao final das quatro sessões de jogos e respostas aos respectivos questionários, foi feita uma entrevista final.

Além desta entrevista, um elenco de 33 heurísticas para avaliação da jogabilidade (Cuperschmid; Hildebrand, 2013) foi aplicada nos quatro jogos por um conjunto de profissionais da área de Informática. Vinte e oito convites foram enviados por e-mail para 23 egressos e cinco alunos do curso de Sistemas de Informação da PUC Minas. Dez avaliadores, sendo sete egressos do curso de Sistemas de Informação, e três alunos do último período, aceitaram participar da avaliação heurística dos quatro jogos utilizados nesta pesquisa. Para avaliar os jogos, os dez avaliadores foram orientados a jogar cada um dos quatro jogos e após cada um deles responder ao questionário de heurísticas de jogabilidade. Os resultados dessa avaliação foram comparados à avaliação feita pelos AMV. 


\subsection{Análise de dados}

Para análise das respostas do questionário os autores propuseram a comparação da média aritmética dos valores atribuídos a cada diretriz em seus respectivos módulos. Para tanto, em relação aos dois módulos utilizados, os autores sugeriram que as perguntas fossem agrupadas de acordo com as seguintes diretrizes:

- Diretrizes de pontuação para o módulo principal do questionário: competência, imersão sensorial e imaginativa, fluxo, tensão/irritação, desafio, sentimento negativo e sentimento positivo;

- Diretrizes de pontuação para o módulo pós-jogo do questionário: experiência positiva, experiência negativa, cansaço e retorno à realidade.

Além da análise de dados dos questionários, as entrevistas foram transcritas e a metodologia da Teoria Fundamentada (Grounded Theory) foi aplicada.

A Teoria Fundamentada em dados, chamada, em inglês, de Grounded Theory, foi proposta por Glaser e Strauss e publicada originalmente em 1967 como uma alternativa para a análise de dados qualitativos (Dick, 2005). O trabalho do pesquisador é descrever uma teoria partindo dos dados, encontrando neles categorias (ou conceitos) e suas propriedades ("subcategorias"), relacionando-as e determinando uma (ou mais de uma) "categoria central" que deve ser descrita para compor a teoria procurada (Dick, 2005). As categorias são encontradas por comparações de dados e são ditas, assim, "emergir" dos mesmos, ou seja, as categorias são "padrões" ou "conceitos" que ocorrem nos dados e que podem explicar os "fenômenos" (problemas, questões, preocupações, assuntos, por exemplo) neles descritos. Não há categorias a priori e estas e as subcategorias são encontradas por três procedimentos sucessivos de codificação: codificação aberta, codificação axial e codificação seletiva.

A codificação aberta é uma série de três passos analíticos para identificar categorias com suas propriedades. Os dados são transcrições de entrevistas e notas de campo ou outros dados (Dick, 2005; Glaser, 2015).

$\mathrm{O}$ passo inicial serve para identificar e dar nomes (rotular) às categorias (conceitos), os quais são rotulados a partir dos dados. No segundo passo os conceitos identificados são agrupados em "categorias abstratas". Essas categorias devem ser capazes de explicar o que está acontecendo. Em seguida, as propriedades das categorias, ou subcategorias (Dick, 2005), são determinadas.

A codificação axial é a etapa em que se busca relacionar as categorias resultantes da etapa de codificação aberta umas às outras e às suas subcategorias que não tenham sido identificadas na codificação aberta, para dar maior poder de explicação sobre os fenômenos.

A codificação seletiva é a etapa cujo objetivo é integrar e refinar as categorias a fim de descrever uma teoria final. Nesse processo, uma (ou mais de uma) "categoria central" é detectada e essa categoria, juntamente com seus relacionamentos com outras categorias e outras informações, compõe a descrição da teoria final.

\section{Resultados e discussões}

No processo de elaboração da teoria fundamentada foram identificadas oito novas categorias as quais foram relacionadas, pensando na relação causa/efeito, originando quatro hipóteses:

- Da categoria "conceito de jogos": O conceito subjetivo e cultural de jogos, que cada adulto mais velho tem, influencia diretamente na relação que esse 
adulto estabelece com o ato de jogar e na motivação ou desmotivação em relação aos jogos;

- Das categorias "afeição ao ato de jogar", "habilidade com a máquina" e "limitação física decorrente da idade": As limitações físicas decorrentes da idade interferem na interação dos adultos mais velhos com o computador;

- Das categorias "relevância de jogos voltados para adultos", "motivação para jogar" e "interface dos jogos": O projeto de jogos voltado para as especificidades de adultos é importante na medida em que previne possíveis problemas que causam desmotivação na hora de jogar;

- Da categoria "aprendizagem por meio de jogos educativos": $O$ projeto de jogos deve possibilitar adaptações didáticas para que atendam às necessidades pedagógicas diagnosticadas pelo professor.

$\mathrm{Na}$ categoria "conceito de jogos" é possível perceber que o conceito subjetivo de jogos de cada participante influenciava quanto ao gostar ou não de jogar. Uma aluna deixou isso explícito em sua fala, quando perguntada sobre o que é um jogo:

"Jogo? Não é de Deus! A bíblia fala que nós somos mais que vencedores e no jogo têm perdedores. Por isso ele não é de Deus. Meu pastor sempre ensina que os jogos vão contra Jesus, tem uns que até fazem matar. Você lembra daquele caso em Ouro Preto?" (referindo-se ao assassinato devido a um RPG ou RolePlaying Game, que é um tipo de jogo de interpretação de papeis).

Culturalmente esses adultos mais velhos trazem uma bagagem que influencia na relação jogador x jogo. Todos, quando convidados a participar da pesquisa, aceitaram participar, mas quando chegou o período de jogar, quatro pessoas, duas do G1 e duas do G2, tiveram certa resistência. Alguns alunos chegaram a faltar de aula nos dias combinados, embora nenhum deles tenha dito claramente, até a primeira sessão de jogos, que não aprovava a ideia de jogar.

Após jogarem a primeira vez, esses preconceitos foram desmitificados. Todos, quando perguntados se jogariam novamente, disseram que sim e cinco deles, entre os seis, pediram o endereço do site para jogar com os filhos e/ou netos. O fato determinante para essa mudança de opinião em relação aos jogos foi que tais jogos trabalhavam com questões pedagógicas, ou seja, enquanto se joga eles estão aprendendo. Cota et al. (2014) ponderam que uma vez que o idoso não conviveu durante a maior parte da sua vida em contato direto com recursos tecnológicos, ele "precisa encontrar nos jogos digitais alguma motivação que o faça ter interesse em realizar esta atividade" (Cota at al., 2014, p. 361). Ijsselsteijn et al. (2007) relatam que o que atrapalha a utilização do jogo pelo adulto mais velho não é a dificuldade de aprender uma nova interface e, sim, a falta de percepção de benefícios em jogos que não os motivam a se envolverem com o conteúdo do mesmo (Ijsselsteijn et al., 2007).

Após iniciarem as sessões, as reclamações deixaram de ser relativas às concepções de jogos e passaram a ser em relação à interação com a máquina e às limitações físicas decorrentes da idade. As principais delas foram a "vista cansada", ter que memorizar as informações e a falta de habilidade com o mouse. Apesar de já estarem familiarizados com os jogos e até manifestarem que estavam gostando, esses fatores interferiam no desempenho dos jogadores e isso provocava certo desconforto percebido em suas fisionomias.

Uma forma de minimizar esses problemas seria desenvolver jogos de computador que atendessem às necessidades específicas de pessoas mais velhas; assim as dificuldades relativas à idade poderiam ser minimizadas. Mas os participantes não entenderam dessa forma. Quando perguntados sobre se preferiam que os jogos fossem voltados para suas necessidades, apenas um respondeu que sim, os outros disseram que 
isso não era importante. Mas, ao responderem os motivos, justificavam externando seus medos, dizendo, por exemplo, que o jogo seria mais difícil se fosse feito para pessoas adultas. Isso revela que eles preferiam os jogos para crianças por julgarem que seria mais fácil ter êxito. Na concepção desses adultos jogos para crianças são mais simples e mais fáceis. Corroborando com a afirmativa de Cota et al. (2014), eles preferem "jogos menos complexos, sem muitas regras a serem observadas durante uma partida, de forma que eles consigam atingir o objetivo sem despender muito esforço mental." (Cota et al., 2014, p. 362).

O conceito subjetivo de jogos e as limitações decorrentes da idade podem influenciar negativamente na experiência que os AMV tem com os jogos. Um meio para minimizar, ou até mesmo extinguir, essa influência das limitações decorrentes da idade é que o projetista de jogos conheça, de forma clara, esses empecilhos e minimize essas dificuldades.

Silva et al. (2014) desenvolveram um jogo para dispositivo móvel com foco em idosos, considerando as restrições visuais e cognitivas que surgem como aumento da idade. Segundo os autores, os jogos digitais podem proporcionar lazer aos idosos, além de manter ou melhorar funções cognitivas. Contudo, para o alcance desses benefícios é necessário que os jogos considerem as restrições decorrentes da idade na confecção da interface.

Outra dificuldade encontrada foi que, ao fazer a avaliação diagnóstica, alguns problemas de aprendizagem foram detectados, mas não foram encontrados jogos que permitissem adaptações didáticas. Por exemplo, nenhum dos participantes conseguiu escrever a letra "k". Contudo em nenhum jogo foi permitido trabalhar com um grupo de palavras que ajudassem a sanar essa lacuna no processo de alfabetização. Ao professor não é permitida intervenção/adaptação alguma com o objetivo de atender às necessidades pedagógicas dos alunos. Isso é crucial pensando-se em jogos educativos.

Em relação a isso, o professor, quando perguntado se acredita que os jogos digitais podem estimular a aprendizagem, deu a seguinte resposta:

"Acredito que pode auxiliar sim! Tanto que utilizo. Mas a tarefa mais complexa

é localizar um jogo que trabalhe especificamente com a necessidade apresentada pelo aluno. Nem sempre isso é possivel."

Johnsen et al. (2007) comprovaram o efetivo aprendizado e a transferência desse aprendizado para ambientes reais quando os jogos digitais são utilizados com a finalidade de educação, avaliação e treinamento. Por isso, é importante que o projeto de jogo sério contemple possíveis alterações por parte do professor, ou mesmo pelo aluno, na hora de jogar. Se o objetivo do jogo sério também é ser educacional, é necessário que o projeto de jogos ofereça a possibilidade de adaptações pedagógicas com o objetivo de atender de forma mais específica às necessidades, diagnosticadas pelo professor, em relação ao processo de alfabetização. Ainda que existam jogos digitais voltados para a alfabetização de adultos mais velhos, isso não é suficiente. É preciso que esses jogos permitam mudanças que se enquadrem no perfil do aluno. Por exemplo, os jogos, ao invés de implementarem um ditado com um número de palavras aleatório, poderiam disponibilizar a escolha de uma ou mais opções de acordo com a necessidade de aprendizado do aluno. Por exemplo, acentuação, pontuação, palavras com "lh", palavras com "s", "z" ou "x".

É preciso chamar a atenção para um fato: dos links indicados pelo professor, nenhum era de jogos para adultos ou mesmo idosos. Quando perguntado sobre isso, o professor afirmou que apesar de ter feito a busca, ele não encontrou. Isso se agrava quando pensamos em adultos ainda em processo de alfabetização: os jogos educativos são voltados para crianças em idade adequada no processo de escolarização. Assim, os 
mais velhos são excluídos duas vezes: em relação ao processo de alfabetização e à inclusão digital.

Outro ponto interessante a ser observado é a questão da sensação de desafio que os participantes tiveram. De acordo com as respostas dadas por eles os jogos eram para crianças e não eram desafiadores, mas ainda assim os jogos despertaram sensações positivas como competência e sentimentos positivos. Pode-se dizer que ao passo que os jogos não traziam desafio, por serem infantis, os AMV conseguiam vencer as etapas e isso lhes trazia a sensação de competência. Isso é relacionado às características de jogabilidade presentes ou ausentes nos jogos que podem ser detectadas por meio de heurísticas (Cuperschmid; Hildebrand, 2013).

De fato, as heurísticas "O jogo deve oferecer diferentes níveis de dificuldade" e "O jogo deve ter múltiplas maneiras de se ganhar", que foram avaliadas como sendo insuficientemente contempladas, são relacionadas à questão do desafio. Conforme foi constatado por meio do questionário de experiência com os jogos, em apenas uma situação, com o grupo dos alunos, G1, no jogo Ditado, o desafio foi classificado como suficiente, sendo insuficiente para todas as outras situações.

É possível perceber que as características denotadas pelas heurísticas que foram avaliadas como insuficientes influenciam diretamente na experiência com os jogos porque dizem respeito às sensações: heurísticas "O jogo não deve apresentar tarefas repetitivas ou entediantes", "Os jogos que envolvem histórias e personagens devem suscitar o interesse pelo que representam" e "O jogo deve ter novidades, surpresas e violação das expectativas". Os termos destacados remetem a sensações que devem ser proporcionadas aos jogadores e que não o foram nos casos aqui estudados.

A falta das características avaliadas por essas cinco heurísticas pode estar influenciando nas sensações negativas e positivas detectadas. Para fins de comparação, foi construído o Gráfico 1 que exibe o somatório dos valores atribuídos para as diretrizes Sentimento positivo e Experiência positiva, Sentimento negativo e Experiência negativa.

Gráfico 1: Porcentagem dos valores atribuídos por jogo

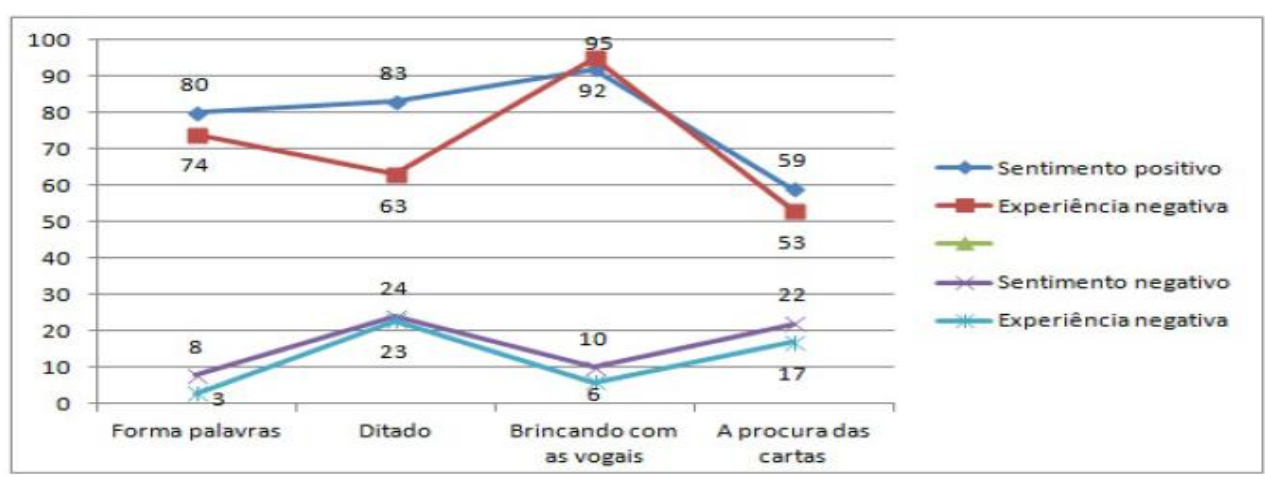

Fonte: Elaborado pela própria autora

A comparação entre o grupo que frequenta uma escola e o grupo que não frequenta indicou que as avaliações e os sentimentos em relação aos quatro jogos selecionados e, em âmbito mais geral, o conceito de jogos, não são divergentes na maioria das vezes. Independente do ambiente, para eles é importante estar aprendendo, ou seja, o jogo não deve ser só um passatempo. 


\section{Conclusões}

Este trabalho buscou apresentar características que jogos educacionais para adultos mais velhos devem possuir. As heurísticas de jogabilidade expostas e avaliadas nesta pesquisa podem ser medidas de avaliação no desenvolvimento de jogos digitais educativos, mas não são suficientes para garantir êxito na utilização desses recursos tecnológicos feita pelos AMV.

Das hipóteses levantadas por meio da Teoria Fundamentada relativas ao projeto de um jogo, apenas a questão da adaptação (heurística "O jogo deve oferecer opções de customização") é prevista nas heurísticas propostas por Cuperschmid e Hildebrand (2013) e ela não foi contemplada nos jogos aqui estudados.

Também foi possível observar que os AMV preferem jogos "fáceis". Dessa forma eles se sentem mais competentes, em detrimento do desafio proporcionado por jogos "difíceis". Isso justifica a preferência por jogos infantis a jogos voltados para jovens e pessoas mais velhas. Contudo, desenvolver jogos voltados para AMV, principalmente em processo de alfabetização, é fundamental, já que o objetivo é minimizar interferências negativas, como aquelas relativas às limitações físicas decorrentes da idade ou dificuldades cognitivas decorrentes da baixa escolarização. Sendo assim, heurísticas de jogabilidade podem contribuir para o desenvolvimento de jogos, mas é necessário considerar as questões específicas que atendam às necessidades dos AMV.

Como trabalhos futuros é possível sugerir um novo estudo de caso em outro contexto, por exemplo, entidades não governamentais ou privadas, com um grupo amostral de AMV com baixa escolaridade para verificar se os resultados obtidos se confirmam; o desenvolvimento e a avaliação de jogos específicos para AMV em processo de alfabetização baseados nos parâmetros encontrados nesta pesquisa e a utilização de tela sensível ao toque como alternativa ao mouse, alterando a forma de interação dos participantes com os jogos, visto que eles reclamaram de dificuldades com o manuseio desse dispositivo.

\section{Referências Bibliográficas}

BRASIL. Alfabetização e Linguagem. Ministério da Educação e Cultura. 2007. Disponível em: <http://portal.mec.gov.br/seb/arquivos/pdf/Proletr/fasciculo_port.pdf>. Acesso em: 20 out. 2014.

BROWNE, K.; ANAND, C.; GOSSE, E. Gamification and serious game approaches for adult literacy tablet software. Entertainment Computing, v. 5, n. 3, p. 135 - 146, 2014. ISSN 1875-9521.

CARVALHO, R. N. S. d.; ISHITANI, L. Fatores motivacionais para desenvolvimento de mobile serious games com foco no público da terceira idade: uma revisão de literatura. ETD - Educação Temática Digital. Campinas. SP. Brasil, v. 15, p. 16-32, Feb. 2013. ISSN 1676-2592.

COTA, T. T.; VIEIRA, N.; ISHITANI, L. Impacto do gênero de jogo digital na motivação dos idosos para jogar. In: PROCEEDINGS OF SBGAMES 2014 CULTURE TRACK - FULL PAPERS ON SBC, XIII, 2014, Porto Alegre, RS, Brasil. [S.1.]: Brazilian Computer Society, 2014. p. 361-368. 
Cuperschmid, A. R. M.; Hildebrand, H. R. Heurísticas de Jogabilidade: Usabilidade e entretenimento em jogos digitais. Campinas, Brasil: Marketing Aumentado, 2013. 134 p. 1 a ed.

DICK, B. Grounded theory: a thumbnail sketch. 2005. Disponível em:

<http://www.aral.com.au/resources/grounded.html>. Acesso em: 28 jan 2015.

GAMES, E. Jogos educacionais. 2015. Disponível em:

<http://www.escolagames.com.br>.Acesso em: 28 jan 2015.

GLASER, B. What is the Grounded Theory. The Grounded Theory Institute. 2015.

Disponível em: <http://www.groundedtheory.com/what-is-gt.aspx >. Acesso em: 28 jan 2015.

IBGE. Síntese de Indicadores Sociais. Uma análise das condições de vida da população brasileira. Instituto Brasileiro de Geografia Estatística. 2010. Disponível em: < http://goo.gl/EJa6gk >. Acesso em: 01 mar 2015.

IBGE. Síntese de Indicadores Sociais. Uma análise das condições de vida da população brasileira. Biblioteca do Instituto Brasileiro de Geografia Estatística. 2013. Disponível em: 〈http://biblioteca.ibge.gov.br/visualizacao/livros/liv66777.pdf>. Acesso em: $01 \mathrm{mar}$ 2015 .

IJSSELSTEIJN, W.; NAP, H. H.; KORT, Y.; POELS, K. Digital game design for elderly users. In: PROCEEDINGS OF THE 2007 CONFERENCE ON FUTURE PLAY. New York, NY, USA: ACM, 2007. (Future Play '07), p. 17-22. ISBN 978-1-59593-9432.

JOHNSEN, K.; RAIJ, A.; STEVENS, A.; LIND, D. S.; LOK, B. The validity of a virtual human experience for interpersonal skills education. In: PROCEEDINGS OF SIGCHI CONFERENCE ON HUMAN FACTORS IN COMPUTING SYSTEMS. [S.1.]: ACM, 2007. p. 1049-1058.

SILVA, H. C. S.; ROQUE, L. Experiência dos jogos digitais aplicados ao envelhecimento ativo. In: PROCEEDINGS OF SBGAMES 2014 CULTURE TRACK - FULL PAPERS ON SBC, XIII, 2014, Porto Alegre, RS, Brasil. [S.1.]: Brazilian Computer Society, 2014. p. 410-419.

SILVA, R. S.; ROCHA, A. A.; NERY, M. S.; MOL, A. M.; ISHITANI, L. Viajando pelo mundo: um projeto de jogo para smartphone com foco em idosos. In: PROCEEDINGS OF SBGAMES 2014 CULTURE TRACK - FULL PAPERS ON SBC, XIII, 2014, Porto Alegre, RS, Brasil. [S.1.]: Brazilian Computer Society, 2014. p. 148-157.

TAMBASCIA, C.; MELO, A. M.; PICCOLO, L. S. G.; ÁVILA, I. M. A. Usabilidade, acessibilidade e inteligibilidade aplicadas em interfaces para analfabetos, idosos e pessoas com deficiência. In: PROCEEDINGS OF THE 10TH BRAZILIAN SYMPOSIUM ON HUMAN FACTORS IN COMPUTINGSYSTEMS, 2008, Porto Alegre, Brasil. Porto Alegre: Brazilian Computer Society, 2008. 